\title{
QUALIDADE DE UVA 'ISABEL' TRATADA COM CLORETO DE CÁLCIO EM PÓS-COLHEITA E ARMAZENADA SOB ATMOSFERA MODIFICADA ${ }^{1}$
}

\author{
ROSANA SOUSA DA SILVA ${ }^{2}$, SILVANDA DE MELO SILVA, ANA LIMA DANTAS ${ }^{4}$, \\ REJANE MARIA NUNES MENDONÇA³ ${ }^{3}$, GEORGE HENRIQUE CAMÊLO GUIMARÃES
}

RESUMO - Uvas 'Isabel' foram tratadas após a colheita com cloreto de cálcio $\left(\mathrm{CaCl}_{2}\right)$ e submetidas a atmosfera modificada para avaliação da manutenção de sua qualidade durante o armazenamento, a $12 \pm 1^{\circ} \mathrm{C} \mathrm{e}$ $85 \pm 2 \%$ de UR. O experimento foi conduzido em delineamento inteiramente casualizado, em esquema fatorial 5 x 2 × 5 , com 3 repetições, sendo cinco doses de $\mathrm{CaCl}_{2}(0,0 ; 0,5 ; 1,0 ; 2,0$ e 4,0\%), dois tipos de atmosfera [ambiente e modificada (AM)] e cinco períodos, durante o armazenamento refrigerado. As avaliações foram acidez titulável (AT), sólidos solúveis (SS), relação SS/AT, pH, ácido ascórbico, incidência de podridão, perda de massa, aparência do engaço e índice de degrana. A AM reduziu a perda de massa, a incidência de podridão e manteve a aparência verde do engaço, ampliando a vida útil de uva 'Isabel' em seis dias. Doses de $\mathrm{CaCl}_{2}$ entre 0,5 e 2,0\% reduziram a incidência de podridão. A aplicação de $\mathrm{CaCl}_{2}$ associado à $\mathrm{AM}$ reduziu a degrana em uva 'Isabel' durante o armazenamento refrigerado.

Termos para indexação: Vitis labrusca, degrana, aparência do engaço, podridão.

\section{QUALITY OF 'ISABEL' GRAPE TREATED WITH CALCIUM CHLORIDE IN POSTHARVEST AND STORED UNDER MODIFIED ATMOSPHERE}

\begin{abstract}
Isabel' grapes were treated postharvest with calcium chloride $\left(\mathrm{CaCl}_{2}\right)$ and in modified atmosphere (MA) aiming its quality maintenance during storage at $12 \pm 1{ }^{\circ} \mathrm{C}$ and $85+2 \% \mathrm{RH}$. The experiment was carried on a completely randomized design, in a factorial scheme $5 \times 2 \times 5$ with three replications, with five levels of $\mathrm{CaCl}_{2}(0,0 ; 0,5 ; 1,0 ; 2,0$ and 4,0\%), two types of atmosphere [room and modified atmospheres (MA)] and five evaluations, during cold storage. The evaluations were titratable acidity (TA), soluble solids (SS), SS/TA ratio, $\mathrm{pH}$, ascorbic acid, decay incidence, mass loss, rachis appearance, and berry drop index. MA reduced mass loss, incidence of decay, and maintained the green rachis appearance. $\mathrm{CaCl}_{2}$ doses among 0,5 and $2,0 \%$ reduced decay incidence. The application of $\mathrm{CaCl}_{2}$ associated with $\mathrm{MA}$ reduced berry drop index in 'Isabel' grape during cold storage.
\end{abstract}

Index terms: Vitis labrusca, berry drop, rachis appearance, decay.

\section{INTRODUÇÃO}

Um dos principais problemas de qualidade da uva de mesa está relacionado com a facilidade de degrana, ou da abscisão das bagas, depois da colheita dos cachos, devido ao desenvolvimento da zona de abscisão (ZHANG; ZHANG, 2009).

A uva de mesa 'Isabel' é uma variedade rústica cujos cachos possuem bagas bastante aglomeradas, rápido amadurecimento e baixa resistência pós-colheita (HESPANHOL-VIANA et al., 2008). Essa variedade de uva de mesa é a mais produzida no Vale do Siriji-PB (IBGE, 2008), cujas principais causas de perdas reportadas pelos produtores estão relacionadas à excessiva degrana, escurecimento do engaço, incidência de podridões, perda de massa e amolecimento das bagas, além de problemas relacionados às embalagens, ao manuseio e ao transporte.

A refrigeração é um dos métodos mais eficientes para a manutenção da qualidade durante o armazenamento de frutos e hortaliças (CHITARRA; CHITARRA, 2005). A atmosfera modificada por filmes flexíveis atua como complemento à redução da temperatura, aumentando a resistência à transferência de $\mathrm{O}_{2}$ e $\mathrm{CO}_{2}$, reduzindo a perda de água, retardando mudanças no teor de açúcares, na coloração e na

\footnotetext{
1'(Trabalho 103-11). Recebido em: 23-03-2010. Aceito para publicação em: 06-03-2012. Suporte financeiro Coordenação de Aperfeiçoamento de Pessoal de Nível Superior (CAPES).

${ }^{2}$ Mestranda em Ciência e Tec. de Alimentos, CT/UFPB, CEP:58059-900, João Pessoa-PB. E-mail: rosanasilva.cta@gmail.com ${ }^{3}$ Prof ${ }^{a}$. Ph.D., CCA/UFPB, CEP:58397-970, Areia-PB. E-mail: silvasil@cca.ufpb.br (Autor correspondente); rejaneufpb@yahoo.com.br ${ }^{4}$ Doutoranda do PPGA, CCA/UFPB, CEP 58397-970, Areia-PB. E-mail: analdantas@gmail.com

${ }^{5}$ Mestrando do PPGA, CCA/UFPB, CEP 58397-970, Areia-PB. E-mail: georgehcg@ibest.com.br
} 
textura, e reduzindo o consumo dos ácidos orgânicos pela diminuição da atividade de enzimas do metabolismo respiratório (TANO et al., 2007).

A influência da aplicação pré-colheita e póscolheita do cloreto de cálcio em uvas tem demonstrado eficiência na manutenção da qualidade e na diminuição das perdas pós-colheita (BRACKMAN et al., 2002; CHERVIN et al., 2009; DANNER et al., 2009; TECCHIO et al., 2009). Os íons de cálcio atuam como retardadores do amadurecimento em frutos, participando na estrutura e na resistência mecânica da parede celular, facilitando ligações entre polímeros de pectina na lamela média (CHITARRA; CHITARRA, 2005).

O objetivo deste estudo foi avaliar a influência da aplicação pós-colheita do cloreto de cálcio $\left(\mathrm{CaCl}_{2}\right)$ associado à atmosfera modificada sobre a qualidade pós-colheita de uva 'Isabel' armazenada sob refrigeração $\left(12 \pm 1^{\circ} \mathrm{C}\right.$ e $85 \pm 2 \%$ de UR).

\section{MATERIAL E MÉTODOS}

O experimento foi conduzido no mês de agosto de 2009, no Laboratório de Biologia e Tecnologia Pós-Colheita do CCA-UFPB. Utilizou-se de cachos de uva 'Isabel' (Vitis labrusca) provenientes de plantio comercial localizado no município de Natuba-PB, situado no Vale do Siriji, latitude sul $7^{\circ} 38^{\prime}$, longitude oeste $35^{\circ} 33^{\prime}$ e altitudes que variam de 180 a $400 \mathrm{~m}$.

Cachos de uva 'Isabel' foram colhidos pela manhã na maturação comercial e conduzidos ao laboratório, onde foram selecionados e imersos durante 10 minutos em soluções de cloreto de cálcio $(0,0 ; 0,5$; 1,$0 ; 2,0$ e 4,0\%), deixados drenar e acondicionados em bandejas de poliestireno expandido. Metade destas bandejas foi revestida por filme de policloreto de vinila (PVC) de $12 \mu \mathrm{m}$ de espessura, promovendo-se atmosfera modificada (AM), e a outra metade permaneceu sem revestimento (atmosfera ambiente -AA). Ambos foram mantidos sob refrigeração a $12 \pm 1{ }^{\circ} \mathrm{C}$ e $85 \pm 2 \%$ de UR durante 12 dias.

O delineamento experimental foi inteiramente casualizado em esquema fatorial $5 \times 2 \times 5$, com três repetições, sendo cada unidade experimental constituída de três cachos. Os fatores estudados foram as cinco doses de $\mathrm{CaCl}_{2}$, atmosfera utilizada (AA e AM) e os períodos de análise $(0 ; 3 ; 6 ; 9$ e 12 dias).

Os frutos foram avaliados quanto aos sólidos solúveis (SS-\%) determinados com refratômetro digital (KRUSS-OPTRONIC, HAMBURGO, ALEMANHA), conforme AOAC (2005); acidez titulável (AT), por titulação com $\mathrm{NaOH} 0,1 \mathrm{M}$ em g.100g ${ }^{-1}$ de ácido tartárico (INSTITUTO ADOLFO LUTZ,
2008); relação SS/AT, quociente entre sólidos solúveis e acidez titulável; $\mathbf{p H}$, medido em potenciômetro digital (HANNA, SINGAPURA), conforme técnica AOAC (2005); ácido ascórbico da polpa, expresso em mg.100 $\mathrm{g}^{-1}$, conforme AOAC (2005); incidência de podridão, expressa em $\%$, determinada pela diferença de massa obtida pela pesagem das bagas sadias e doentes para cada cacho; perda de massa fresca, expressa em \%, realizando-se pesagem das repetições diariamente, calculando-se a proporção diária de perda tomando como base o peso inicial; aparência do engaço, foi avaliada utilizando-se da seguinte escala: 0- para engaços verdes, túrgidos, com aspecto fresco de recém-colhidos; 5- para engaços verdes e levemente secos (verde opaco); 10- para verdes com pontuações marrons, levemente secos; 15para marrons, secos, e 30- para engaços marrons, muito secos, quebradiços (GOMES, 2006); índice de degrana, expresso em $\%$, foi determinado pela diferença de massa obtida pela pesagem dos cachos e das bagas degranadas, agitando manualmente por cinco vezes (TECCHIO et al., 2009).

Os dados foram submetidos à análise de variância e de regressão, exceto pelos de degrana que foram submetidos à análise de deviance e regressão logística (MENESES et al., 2011), sendo as médias das duas atmosferas comparadas pelo teste $\mathrm{F}$, a $5 \%$ de probabilidade. Os ajustes e as análises estatísticas foram realizados com base no procedimento GENMOD do sistema estatístico SAS ${ }^{\circledR}$ system/STAT 9.1.1.3 (2006).

\section{RESULTADOS E DISCUSSÃO}

Com relação ao tratamento com $\mathrm{CaCl}_{2}$ a perda de massa foi menor em uvas sob AM, sendo em média de 2,14\%. A perda de massa foi superior em uvas sob AA, com declínio na dose de $4 \%$ de $\mathrm{CaCl}_{2}$ (Figura 1A). A perda de massa durante o armazenamento foi linear crescente para ambas as atmosferas empregadas, sendo menor $(\mathrm{p}<0,01)$ sob AM (Figura 1B), como em uvas 'Dona Zilá' (BRACKMANN et al., 2002).

Danner et al. (2009) reportaram redução da perda de massa em relação à testemunha de uva 'Vênus' sob diferentes fontes de cálcio na pré-colheita. Em morangos, o cálcio resultou em menor perda de massa durante o armazenamento (HERNÁNDEZMUÑOZ et al., 2006), que em pêssego foi atribuído à manutenção da estrutura das paredes celulares por esse cátion (MANGANARIS et al. 2007), minimizando assim a perda de água.

Os sólidos solúveis ( $\mathrm{SS}$ ) foram superiores em uvas sob AA (Figura 2A), cuja mais elevada perda de massa pode ter contribuído para o aumento dos 
SS nas bagas (BRACKMANN et al., 2002). As uvas 'Isabel' estudadas neste trabalho apresentaram média de SS de $14,43 \%$ no sexto dia de armazenamento. De acordo com o Regulamento Técnico de Identidade e Qualidade para a classificação de uva rústica, da Lei $\mathrm{n}^{\circ}$ 9.972, de 25 de maio de 2000 (BRASIL, 2000), a porcentagem mínima de sólidos solúveis (SS) em uva rústica para consumo é de $14 \%$.

Frutos não climatéricos, como a uva, apresentam poucas modificações no teor de açúcares, no período pós-colheita (TECCHIO et al., 2009). Em alguns frutos não climatéricos, no entanto, pode ocorrer aumento no teor inicial de açúcares, devido à degradação de polissacarídeos da parede celular (CHITARRA; CHITARRA, 2005). Por outro lado, Danner et al. (2009) observaram que o teor de SS em uvas 'Venus' também não variou, independentemente da fonte de cálcio aplicada no solo.

Em uva 'Isabel', o pH, o ácido ascórbico e a degrana foram significativamente afetados tanto pelo emprego de atmosfera modificada quanto pelo $\mathrm{CaCl}_{2}$.

A acidez titulável (AT) foi superior em uvas 'Isabel' mantidas sob AA, observando-se aumento durante o armazenamento tanto para bagas sob AA quanto sob $\mathrm{AM}$ até o $9^{\circ}$ dia, tendendo a diminuir em seguida (Figura 2B). Com relação às doses de $\mathrm{CaCl}_{2}$, a acidez aumentou durante $\mathrm{o}$ armazenamento, exceto para $4 \%$, na qual a AT foi relativamente constante (Figura 2C).

Maneguzzo et al. (2006) relatam que o aumento da AT está associado à perda de massa das bagas e à formação dos ácidos glicônico e pirúvico, quando também correlacionou o efeito da podridãocinzenta com o aumento da acidez total em uvas viníferas. Danner et al. (2009) observaram que a AT de uva 'Venus' não diferiu da testemunha quanto às diferentes fontes de cálcio aplicadas ao solo. Tecchio et al. (2009) observaram aumento da AT com dose de $1,0 \%$ de $\mathrm{CaCl}_{2}$ aplicado na pré-colheita em uvas, associando ao acúmulo de ácidos orgânicos durante o armazenamento devido à redução da taxa respiratória.

$\mathrm{O}$ aumento da AT resultou em redução da relação SS/AT durante o armazenamento, que foi superior para uvas mantidas sob AM (Figura 2D). A relação SS/AT é indicativa de sabor e aceitação de uvas (MASCARENHAS et al., 2012).

Com relação ao pH, a uva 'Isabel' mantevese entre 2,98 e 3,30, dentro da faixa reportada por Mascarenhas et al. (2010) e Rizzon e Link (2006). Entre as doses de $\mathrm{CaCl}_{2}$ verificou-se que o $\mathrm{pH}$ das bagas foi superior nas mantidas sob AM (Figura 3A).

Ao contrário das bagas sob AA, o teor de ácido ascórbico na polpa da uva 'Isabel' aumentou com as doses de $\mathrm{CaCl}_{2}$ em frutos mantidos sob AM, exceto para a dose de $4,0 \%$, que tendeu a diminuir (Figura 3B).
Em geral, a manutenção do teor de ácido ascórbico sob AM foi explicado pelo fato de a modificação da atmosfera ter possivelmente proporcionado menor disponibilidade de $\mathrm{O}_{2}$ dentro da embalagem (TANO et al., 2007) e, consequentemente, reduzido sua taxa de oxidação deste composto com propriedades antioxidantes.

Embora a incidência de podridão tenha aumentado durante o armazenamento, as doses entre 0,5 e $2,0 \%$ de $\mathrm{CaCl}_{2}$ resultaram em menores índices ao final do período (Figura 3C). O emprego de AM foi efetivo em reduzir a incidência de podridão em uvas 'Isabel' durante o armazenamento (Figura 3D), que se manifestou após 6 dias, sobretudo nas uvas conservadas sob atmosfera ambiente. Tecchio et al. (2009) observaram que $\mathrm{CaCl}_{2}$, associado a ácido naftalenoacético aplicado na pré-colheita, reduziu a incidência de podridão em uva 'Niágara Rosada' após 21 dias de armazenamento sob refrigeração. A incidência de podridão-cinzenta em uva de mesa foi reduzida pela aplicação de $\mathrm{CaCl}_{2}$ e etanol na pré-colheita (CHERVIN et al., 2009). Em uva 'Dona Zilá', a incidência de podridão foi também diminuída pela aplicação de $1,5 \% \mathrm{CaCl}_{2}$ na pós-colheita (BRACKMANN et al., 2002).

Verificou-se que as uvas 'Isabel' armazenadas sob AM apresentaram menor escurecimento do engaço (Figura 4A) após 6 dias de armazenamento. Tal fato pode ser explicado pela menor perda de água em cachos mantidos em AM, retardando o ressecamento do engaço e a consequente manutenção da cor verde.

O índice de degrana diminuiu com o aumento das doses de $\mathrm{CaCl}_{2}$ (Figuras $4 \mathrm{~B}$ e $4 \mathrm{C}$ ), conforme também reportado por Brackmann et al. (2002), que também constataram que a resistência da baga à degrana aumentou conforme o aumento dos níveis de $\mathrm{CaCl}_{2}$ aplicado na pós-colheita, sobretudo sob atmosfera modificada. A abscisão da uva está associada com o aumento das atividades das hidrolases da zona de abscisão, particularmente das enzimas celulases e poligalacturonase (DENG et al., 2007). Danner et al. (2009) demonstraram que o $\mathrm{CaCl}_{2}$, aplicado na pré-colheita, reduziu a degrana de bagas, que, conforme Deytieux-Belleau et al. (2008), é uma consequência da redução da atividade das enzimas poligalacturonase e pectinametilesterase, cuja elevação da atividade enzimática está correlacionada com o aumento da degrana das bagas (DENG et al., 2007). Desse modo, por preservar a integridade da parede celular, vários trabalhos indicam que o $\mathrm{Ca}^{2+}$ auxilia na preservação da qualidade pós-colheita (CHERVIN et al., 2009; DEYTIEUX-BELLEAU et al., 2008; HERNÁNDEZ-MUÑOZ et al., 2006). 

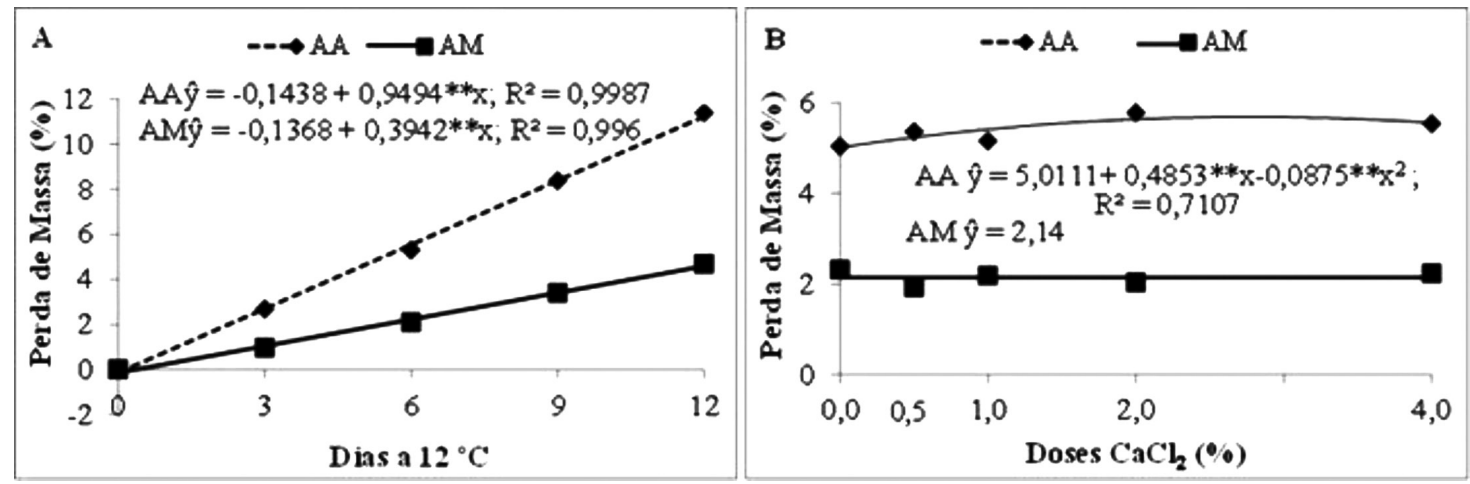

FIGURA 1- Perda de massa (\%) de uva 'Isabel' durante o armazenamento por 12 dias a $12 \pm 1{ }^{\circ} \mathrm{C}$ e $85 \pm 2 \%$ UR submetida a atmosferas ambiente (AA) e modificada (AM) (A) e tratada com cloreto de cálcio $\left(\mathrm{CaCl}_{2}\right)(0,0 ; 0,5 ; 1,0 ; 2,0$ e 4,0\%) (B), após 12 dias de armazenamento sob AA e AM, ambos sob refrigeração.

**Significativo a $1 \%$ de probabilidade, pelo teste $\mathrm{F}$.
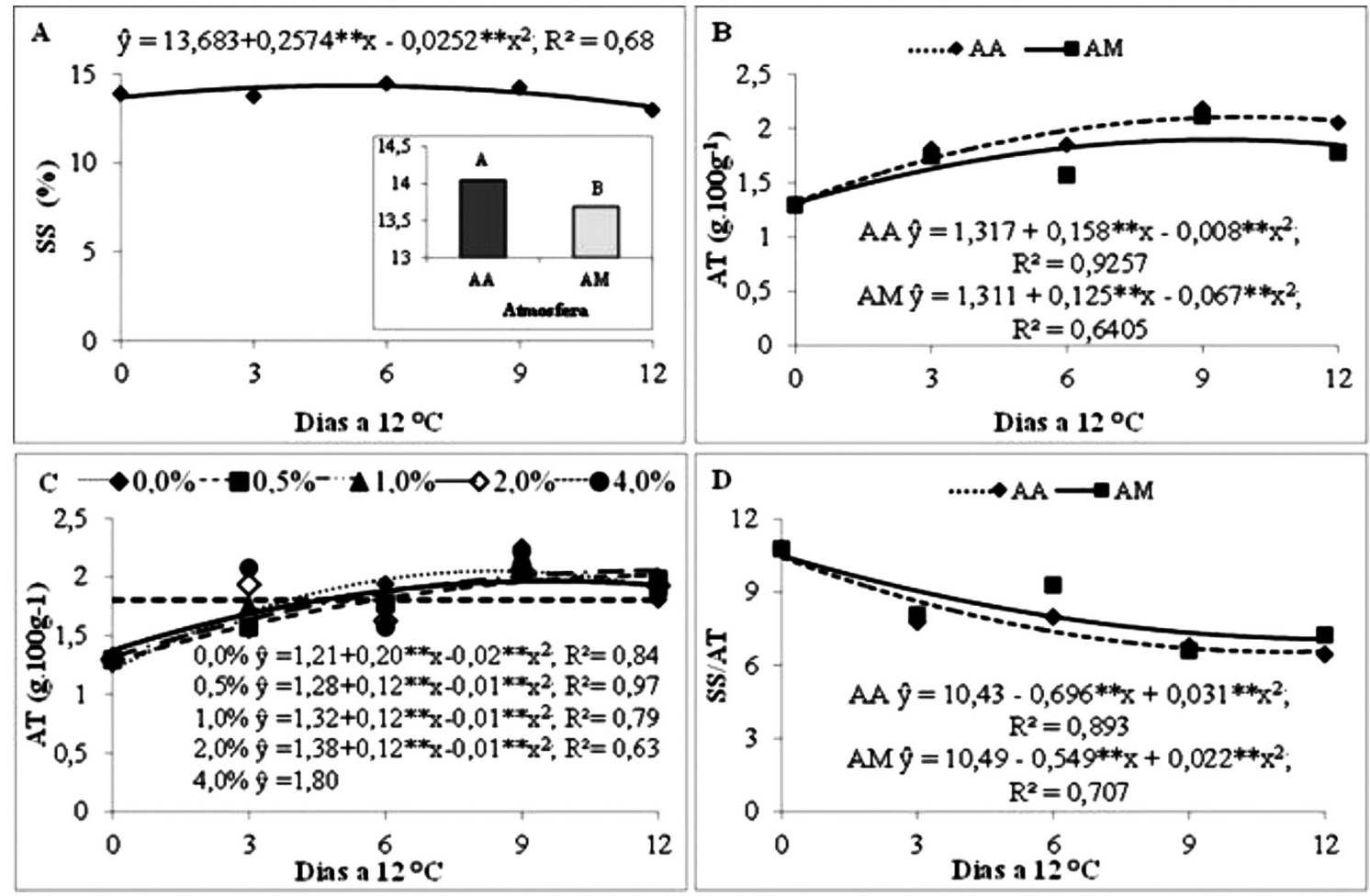

FIGURA 2- Sólidos solúveis (SS-\%) sob atmosferas ambiente (AA) e modificada (AM) (A), acidez titulável (AT- g ácido tártarico. $100 \mathrm{~g}^{-1}$ ) sob AA e AM (B), AT de bagas tratadas com cloreto de cálcio $\left(\mathrm{CaCl}_{2}\right)(0,0 ; 0,5 ; 1,0 ; 2,0$ e 4,0\%) (C) e relação SS/AT sob AA e AM (D), em uva 'Isabel', durante 12 dias de armazenamento a $\left(12 \pm 1^{\circ} \mathrm{C}\right.$ e $85 \pm 2 \%$ UR). 

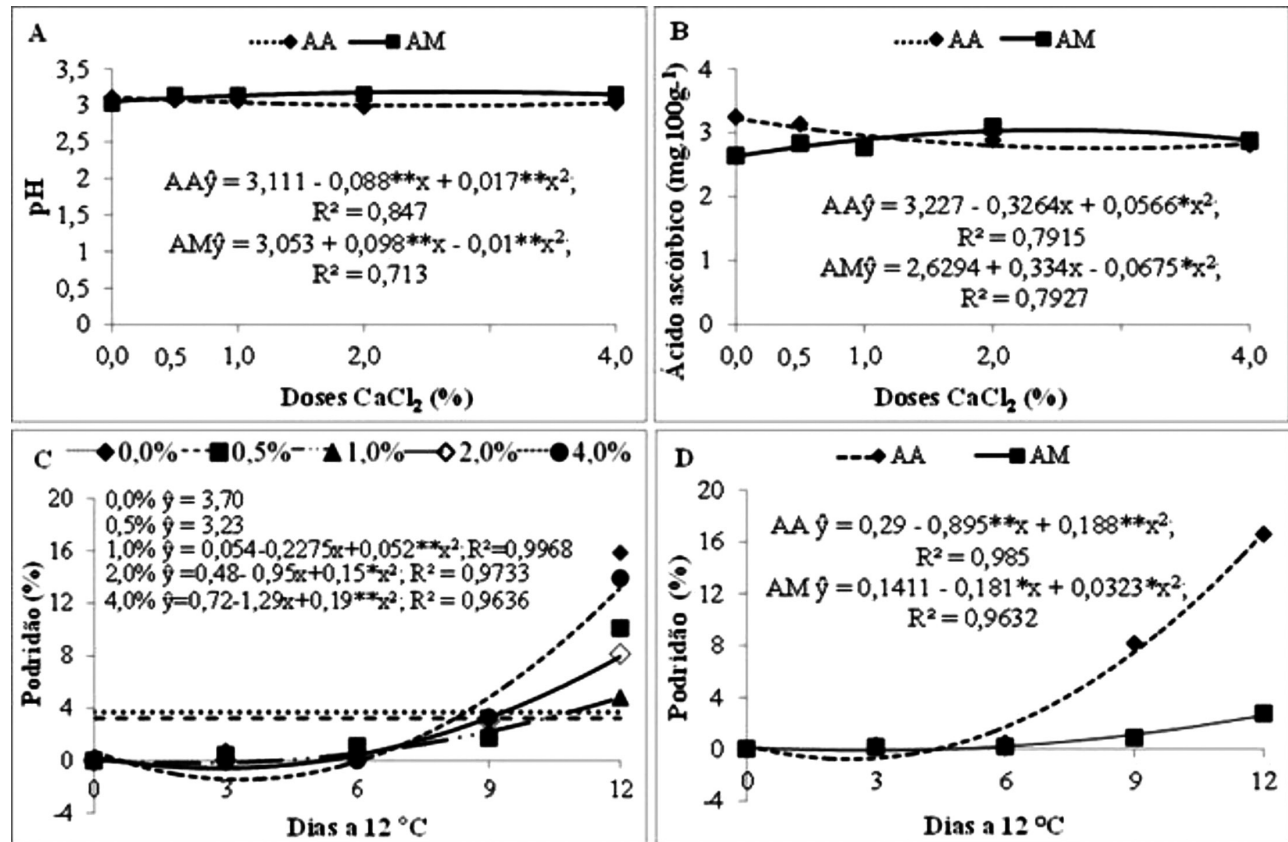

FIGURA 3- pH (A) e ácido ascórbico (mg.100 g-1) (B) em bagas tratadas com de cloreto de cálcio $\left(\mathrm{CaCl}_{2}\right)$ $(0,0 ; 0,5 ; 1,0 ; 2,0$ e 4,0\%), após 12 dias de armazenamento sob atmosferas ambiente (AA) e modificada (AM), e podridão durante o armazenamento de bagas tratadas com $\mathrm{CaCl}_{2}(\mathrm{C})$ e no armazenamento a $12 \pm 1{ }^{\circ} \mathrm{C}$ e $85 \pm 2 \%$ UR em AA e AM (D).

**Significativo a $1 \%$ de probabilidade, pelo teste $\mathrm{F}$

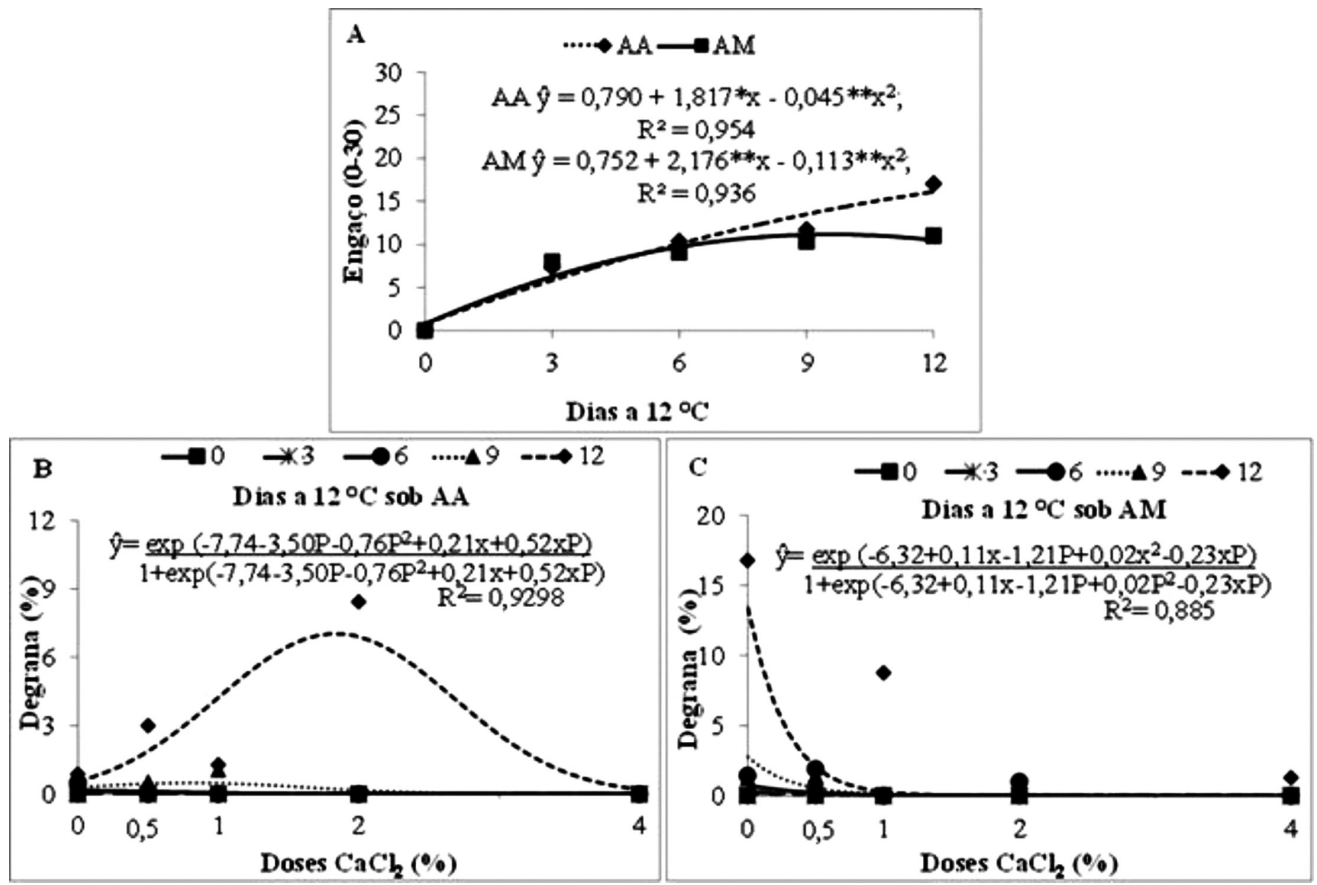

FIGURA 4- Aparência do engaço (notas: 0-30) durante 12 dias de armazenamento (A) e índice de degrana em função das doses de $\mathrm{CaCl}_{2}(0,0 ; 0,5 ; 1,0 ; 2,0$ e 4,0\%) e períodos de armazenamento em atmosferas ambiente (AA) (B) e modificada (AM), em uva 'Isabel' mantidas a $12 \pm 1{ }^{\circ} \mathrm{C}$ e $85 \pm 2 \%$ UR.

**Significativo a 1\% de probabilidade, pelo teste F; P: período; $\mathrm{x}$ : doses $\mathrm{de} \mathrm{CaCl}_{2}$ 


\section{CONCLUSÃO}

$\mathrm{O}$ uso de filme de policloreto de vinila com $12 \mu \mathrm{m}$ mantém a vida útil de uva 'Isabel' por 12 dias sob refrigeração a $12{ }^{\circ} \mathrm{C}$ e $85 \pm 2 \%$ de UR. A atmosfera modificada preserva a aparência do engaço e promove a redução da perda de massa e da incidência de podridões por seis dias a mais que frutos não embalados. A associação de atmosfera modificada com a aplicação de 1,0 a $2 \%$ de $\mathrm{CaCl}_{2}$ em pós-colheita reduz a degrana durante o armazenamento a $12 \pm 1^{\circ} \mathrm{C}$.

\section{AGRADECIMENTOS}

À CAPES, pela Bolsa ao primeiro autor, e ao $\mathrm{CNPq}$, pelo apoio financeiro.

\section{REFERÊNCIAS}

AOAC- Official methods of analysis of the Association of Official Analytical Chemistry. $18^{\text {th }} \mathrm{ed}$. Gaitherrsburg: AOAC, 2005.

BRACKMANN, A.; VIZZOTTO, M.; CERETTA, M. Qualidade de uvas cvs. Dona Zilá e Tardia de Caxias sob diferentes condições de armazenamento. Revista Ciência e Agrotecnologia, Lavras, v. 26, n.5, p. 1019-1026, 2002.

BRASIL. Ministério da Agricultura e Pecuária. Instrução Normativa, Lei no 9.972 de 25 de maio de 2000. Regulamento técnico de identidade e qualidade para a classificação da uva rústica. Brasília: MAPA, 2000.

CHERVIN, C.; LAVIGNE, D.; WESTERCAMP, P. Reduction of gray mold development in table grapes by preharvest sprays with ethanol and calcium chloride. Postharvest Biology and Technology, Louven, v. 54, p. 115-117, 2009.

ChitarRa, M. I. F.; CHITARRA, A. B. Pós-colheita de frutos e hortaliças: fisiologia e manuseio. 2.ed. Lavras: UFLA, 2005. 785p.

DANNER, M. A.; CITADIN, I.; SASSO, S. A. Z.; ZARTH, N. A.; MAZARO, S. M. Fontes de cálcio aplicadas no solo e sua relação com a qualidade da uva 'Vênus'. Revista Brasileira de Fruticultura, Jaboticabal, v. 31, n.3, p. 881-889, 2009.
DENG,Y.; WU, Y. ; LI, Y. ; YANG, M. ; SHI, C. ; ZHENG, C. A mathematical model for predicting grape berry drop during storage. Postharvest Biology and Technology, Amsterdam, v. 43, p. 95-101, 2007.

DEYTIEUX-BELLEAU, C.; VALLET, A.; DONÈCHE, B.; GENY, L. Pectin methylesterase and polygalactoronase in developing grape skin. Plant Physiology and Biochemistry, Brussels, v. 46, p. 638-646, 2008.

GOMES, D. Efeitos da vibração na qualidade da uva 'Niágara Rosada'. 2006. 84 f. Dissertação (Mestrado em Engenharia Agrícola) - Universidade Estadual de Campinas, Campinas, 2006.

HERNÁNDEZ-MUÑOZ, P.; ALMENAR, E.; OCIO, M.J.; GAVARA, R. Effect of calcium dips and chitosan coatings on postharvest life of strawberries (Fragaria $\mathrm{x}$ ananassa). Postharvest Biology and Technology, Amsterdam, v.39, n.3, p.247-253, 2006.

HESPANHOL-VIANA, L.; POMMER, C.V.; VIANA, A.P.; CAMPOSTRINI, E. Avaliação da aderência ao pedicelo das bagas de algumas variedades de uva de mesa. 2008. Disponível em: $<$ http://www.infobibos.com/Artigos/2008 3/UvaMesa/index.htm>. Acesso em: 24 nov. 2010.

IBGE. Produtos das lavouras permanentes. 2008. Disponível em: http:<//www.sidra.ibge.gov.br/>. Acesso em: 9 set. 2010.

INSTITUTO ADOLFO LUTZ. Métodos físicoquímicos para análise de alimentos. 4. ed. São Paulo, 2008. 1020 p.

MANGANARIS, G.A.; VASILAKAKIS, M.; DIAMANTIDIS, G.; MIGNANI, I. The effect of postharvest calcium application on tissue calcium concentration, quality attributes, incidence of flesh browning and cell wall physicochemical aspects of peach fruits. Food Chemistry, New York, v.100, n.4, p.1385-1392, 2007.

MASCARENHAS, R. J.; SILVA, S. M.; LIMA, M.A.C.; MENDONÇA, R.M.N.; HOLSCHUH, H.J. Characterization of maturity and quality of Brazilian apirenic grapes in the São Francisco river Valley. Revista Ciência e Tecnologia de Alimentos, Campinas, v. 32, n.1, 2012. 
MASCARENHAS, R. J.; SILVA, S. M., LOPES, J.D.; LIMA, M.A.C. Avaliação sensorial de uvas de mesa produzidas no Vale do São Francisco e comercializadas em João Pessoa - PB. Revista Brasileira de Fruticultura, Jaboticabal, v. 32, n.4, p. 993-1000, 2010.

MENEGUZZO, J.; RIZZON, L. A.; MIELE, A.; AYUB, M. A. Z. Efeito de Botrytis cinerea na composição do vinho Gewürztraminer. Revista Ciência e Tecnologia de Alimentos, Campinas, v. 26, n.3, p. 527-532, 2006.

MENESES, C. H. S. G.; BRUNO, R. L. A.; FERNANDES, P. D.; PEREIRA, W. E.; LIMA, L. H. G. M.; LIMA, M. M. A.; VIDAL, M. S. Germination of cotton cultivar seeds under water stress induced by polyethyleneglycol-6000. Scientia Agricola, Piracicaba, v.68, n.2, p. 131-138, 2011.

RIZZON, L. A.; LINK, M. Composição do suco de uva caseiro de diferentes cultivares. Revista Ciência Rural, Santa Maria, v. 36, n.2, p. 689-692, 2006.
SAS INSTITUTE. SAS/STAT® 9.22 User's guide. Cary, 2006. 444 p.

TANO, K.; OULÉ, M.K.; DOYON, G.; LENCKI, R.W.; ARUL, J. Comparative evolution of the effect of storage temperature fluctuation on modified atmosphere packages of selected fruits and vegetables. Postharvest Biology and Technology, Louven, v. 46, p. 212-221, 2007.

TECCHIO, M. A.; TERRA, M. M.; CIA, P.; PAIOLI-PIRES, E.J.; MOURA, M. F.; SANCHES, J.; BENATO, E. A.; HERNANDES, J. L.; VALENTINI, S. R. T.; SIGRIST, J. M. M. Efeito do ácido naftalenoacético e do cloreto de cálcio na redução das perdas pós-colheita em uva 'Niágara Rosada'. Revista Brasileira de Fruticultura, Jaboticabal, v. 31, n.1, p. 53-61, 2009.

ZHANG, Y. L.; ZHANG, R. G. Effects of ABA content on the development of abscission zone and berry falling after harvesting of grapes. Agricultural Sciences in China, China, v. 8, n.1, p. 59-67, 2009. 